\title{
Moving beyond the weekend effect: how can we best target interventions to improve patient care?
}

\author{
Perla J Marang-van de Mheen (D) , ${ }^{1}$ Charles Vincent (D) ${ }^{2}$
}

${ }^{1}$ Department of Biomedical Data Sciences, J10-S, Leids Universitair Medisch Centrum, Leiden, The Netherlands ${ }^{2}$ Department of Experimental Psychology, University of Oxford, London, UK

\section{Correspondence to} Dr Perla J Marang-van de Mheen, Department of Biomedical Data Sciences, J10-S, Leids Universitair Medisch Centrum, PO Box 9600, 2300 RC Leiden, The Netherlands; p.j.marang-van_de_mheen@ lumc.nl

Accepted 2 February 2021 Published Online First 11 February 2021

\section{SLinked}

- http://dx.doi.org/10.1136/ bmjqs-2020-011165

\section{Check for updates}

(C) Author(s) (or their employer(s)) 2021. No commercial re-use. See rights and permissions. Published by BMJ.

To cite: Marang-van de Mheen PJ, Vincent C. BMJ Qual Saf

2021;30:525-528.
Clear evidence for a weekend effect was first demonstrated by Bell and Redelmeier $^{1}$ who examined 3.8 million emergency admissions between 1988 and 1997 in an acute care hospital in Ontario. They had noted that staffing levels were lower in acute care hospitals at weekends and hypothesised that this might lead to poorer care and higher mortality. To test this hypothesis, they identified three conditions (ruptured abdominal aortic aneurysm, acute epiglottitis and pulmonary embolism) for which lower staffing on admission was expected to have consequences in outcomes, as well as three control conditions for which this would not be the case. In addition, they conducted an analysis without a prespecified hypothesis, examining the 100 conditions responsible for most deaths. After adjustment for illness severity, they found higher mortality for conditions expected to be affected by lower staffing and no increase for control conditions. From the 100 medical conditions examined, 23 had significantly increased mortality risk for weekend admissions. These two sets of findings provided strong evidence for a weekend effect, suggesting that for some conditions lower staffing on admission affected standards of care and thereby patient outcomes.

Since then, dozens of studies of the weekend effect have been conducted, mostly in the UK and the USA. ${ }^{2}$ In Britain, the issue became much more high profile after an intervention in 2015 by the Secretary of State who suggested that 11000 patients were unnecessarily dying at the weekend. ${ }^{3}{ }^{4}$ This claim was challenged at the time, ${ }^{5}$ and many pointed out that the National Health Service (NHS) was already a 7 -day service. ${ }^{67}$ However, concern about the weekend led eventually to the introduction of ' 7 day services' in the NHS in England. A new set of 10 clinical standards was introduced to reduce differences between weekend and weekday services, including increased involvement of consultants in the first 24 hours of admission. ${ }^{8}{ }^{9} \mathrm{~A}$ cross-sectional analysis covering the period before introduction showed no association between specialist intensity and weekend admission mortality. ${ }^{10}$ Nevertheless, the programme did lead to many NHS hospital trusts reorganising services to reduce differences in care delivery across the 7-day week. The reorganisation of services did not affect clinical outcomes ${ }^{11}$ nor was adoption of the clinical standards associated with any significant change in the magnitude of the weekend effect. ${ }^{12}$

\section{POSSIBLE UNDERLYING MECHANISMS: THE WEEKEND AS PROXY VARIABLE}

Recent systematic reviews have concluded that the weekend effect does exist, but the explanation for the finding is unclear. $^{2}{ }^{4} 13-17$ Patients admitted to hospital at the weekend are more likely to die than those during weekdays with ORs of 1.16 (all studies) $^{2}$ and 1.07 (UK studies), ${ }^{4}$ with reviews for some specific disease categories reporting higher ORs. $^{2}{ }^{13}$ The quality of studies is highly variable, with findings being influenced by methodological, clinical and service configuration factors ${ }^{2}$ with ongoing debate about likely mechanisms. Why has it been so difficult to elucidate possible mechanisms? To go more deeply into this, we need to consider what role the weekend is playing in the design of all these studies.

Bell and Redelmeier ${ }^{1}$ used two distinct designs in their original investigation, which might best be defined as an investigation of staffing levels and mortality. 
In their first analysis, the weekend is used as a proxy measure for differences in staffing. They targeted specific conditions such as ruptured abdominal aortic aneurysm for which staffing on admission was deemed likely to have an important impact on patient outcomes. Their second analysis took the opposite approach, by examining overall outcomes at the weekend and then speculating about which factors might explain any observed differences. Most subsequent studies have used the second approach, which has made it difficult to make progress on identifying the relevant factors driving any effect. If we do not define the questions and hypothesised relationships precisely, then we will not be able to identify how care delivered to patients is affected and which factors are responsible for poorer outcomes. Critically, if we cannot identify the factors, then we cannot intelligently propose interventions to improve patient care.

We therefore need to examine how the weekend as a proxy variable for staffing levels fits into the conceptual model. Is the proxy only associated with the determinant, often assumed to be staffing levels, or also with other possible confounders or factors that affect the outcome in question? We recognise there are multiple possible sets of relationships, but examining three of them is sufficient to make the general argument. Figure 1 displays three possible sets of relationships, which correspond with three broad hypotheses about potential mechanisms and hence the interpretation of the weekend effect.

\section{Levels of staffing on admission is the dominant influence on quality of care and mortality (panel A)}

This shows the 'ideal' and simplest situation when the proxy weekend/weekday variable is primarily associated with staffing in the first hours or days. The implied mechanism is that lower numbers of staff, particularly senior staff, lead to poorer care and increased mortality. In that situation, weekendweekday mortality differences, after adjustment for patient mix, can be presumed to be due to staffing differences. Bell and Redelmeier specifically tested this scenario by selecting those conditions for which the first few days of admission are critical, that are treatable and where death may be rapid. For these conditions, insufficient staffing levels at admission (determinant) might cause delay in care processes (intermediate variable) and higher mortality (outcome).

\section{Patients at weekends are sicker and more likely to die (panel B)}

As many studies have shown, the weekend is associated with confounding variables. Patients admitted at the weekend are known to be sicker ${ }^{18} 19$ and are less likely to be admitted from emergency departments despite attendance rates being similar. ${ }^{16} 20$ Studies attempt to control for severity of condition and other confounders, but there is general agreement that it is
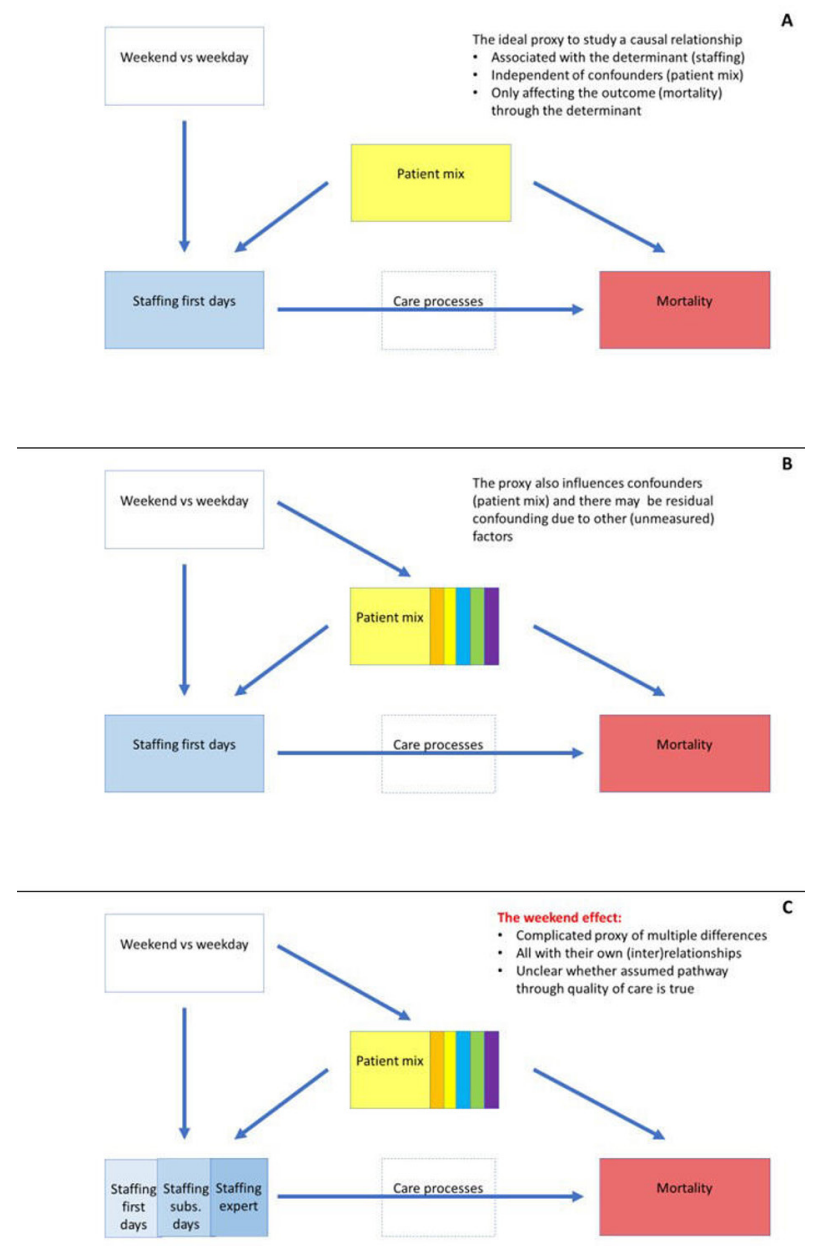

Figure 1 Proxy measures in the context of studying a determinant - outcome relationship, applied to the weekend as a proxy variable for staffing.

simply not possible to control for all potential factors (and confounding by indication). There is always the possibility that, even after adjustment for severity of illness and other patient variables, that differences in outcome are due to other patient factors that, for whatever reason, could not be included in the calculations. So for many conditions, this is an important alternative pathway to consider.

\section{Multiple factors affect care at the weekend, which in turn increases mortality (panel C)}

This model underlies the second approach by Bell and Redelmeier and many subsequent studies. The basic hypothesis is that patient outcomes differ between weekend and weekday, but this may be due to multiple relationships and multiple interrelated variables. For instance, the average seniority or specialty level may differ between the groups of nurses and medical staff working during weekdays and weekends, and such differences in skill-mix may affect patient outcomes. ${ }^{21-23}$ Access to diagnostic tests or other ancillary services might also differ between weekends and weekdays, or there may be factors further along the 
patient pathway (in subsequent days after admission) such as how quickly any deterioration on the ward is detected. In this scenario, uncertainty about the mechanisms of the weekend effect makes it very difficult to identify targeted interventions to improve outcomes for patients admitted at the weekend.

\section{THE ASSUMED INTERMEDIATE VARIABLE OF WORSE QUALITY OF CARE}

Hypotheses 1 and 3 have the same intermediate variable, that quality of care is poorer at the weekendalthough for different reasons-and that this is the reason for higher mortality. Investigating this particular proposal requires, as many have noted, 'painstaking detective work', ${ }^{24}$ but few studies have directly examined the quality of care provided during weekdays and at weekends. In this issue of BMJ Quality \& Safety, Bion and colleagues therefore add crucial evidence with their impressive and comprehensive study. ${ }^{25}$ They reviewed the quality of care delivered by examining case records from 4000 non-operative medical emergency admissions in 20 acute hospital trusts before and after introduction of the '7-day services' in England. Records were randomly sampled from each trust, equally divided between the two time periods and weekend versus weekday admissions. They found that rates of errors and adverse events were not significantly different between weekdays and weekends and that this was the case both before and after introduction of the '7-day services'. They also made a direct assessment of intensity of senior medical staffing by comparing hours of consultant time per 10 emergency admissions between Sundays and Wednesdays. This specialist intensity ratio was much lower at weekends (0.51 overall) and improved slightly (from 0.47 to 0.58 ) across periods. Their study therefore does not offer support for quality of care being worse at the weekend or that senior staff involvement at an early point in the patient's admission is significantly associated with overall quality of care. We should note, however, that operative patients were excluded, so it remains possible that care is poorer for some other groups of patients.

The implicit assumption in many previous studies, and most political discourse, is that the weekend is simply a reflection and proxy for lower levels of skilled staff, particularly medical staff. Proxy variables are of course used all the time in research and can be very helpful if they are 'close' to the variable of interest. For instance, we might use the prescription record of a medication as a proxy for the actual medication administered to the patient. We are then confident of what the proxy means and how it relates to the actual variable of interest. Even though some patients may decide not to collect their medication or be non-adherent in taking it, interpreting the proxy is relatively straightforward.
In contrast, the weekend/weekday comparison is a distant and complex proxy. Care could potentially be different for a whole variety of reasons, which are only partly dependent on levels of skilled medical staff. Diagnostic tests and investigations may not be readily available; coordination between different specialties may be problematic within the hospital or between primary and secondary care and so on. Each of these may cause delay in a care process that may (in combination) affect patient outcomes. In addition, conditions vary in the extent to which delays in the first few days are critical in preventing death. Some primarily require skilled staff on admission, while others are more vulnerable to later deterioration on wards and need care from experienced nurses in the days following admission.

\section{SHOULD WE CONTINUE STUDYING THE WEEKEND EFFECT?}

We do not doubt that studies of the weekend effect have been worthwhile. Clearly, the higher mortality at weekends originally identified 20 years ago merited investigation. The question is whether it is worthwhile to continue to conduct similar studies in the future given the limited funding and research time available. What avenues of inquiry are most likely to benefit patients?

The ultimate aim of all concerned is to improve care given to patients. The weekend effect is only important as a potential marker of other problems. Local reviews of mortality or other indices of quality should always be alert to variations in the quality of care over the week, and consider whether care is poorer at weekends or indeed at any particular time of the day, week or year. However, we consider that there is no reason to carry out further studies that simply demonstrate a weekend effect. We need instead to turn our attention to the factors directly influencing quality of care for which the weekend has been a proxy.

Bion and colleagues provide a valuable illustration of research that examines the presumed causal relationships, looking at the actual care processes and so give a clearer indication of what kind of intervention might most benefit patients. Their study found that care had improved over time but that about $15 \%$ of patients received partial care and a small percentage received very poor care. ${ }^{25}$ These problems occurred throughout the week, affecting the larger volume of patients treated on weekdays. Following the example of the study by Bion et al, future studies could directly assess standards of care and the factors that most powerfully influence quality. A notable example is the study by Jayawardana and colleagues, ${ }^{26}$ showing that the increased mortality for out-of-hours admissions with ST-elevation acute myocardial infarction was explained by differences in door-to-needle time, identifying the specific care process on which interventions should be targeted. To improve clinical practice, we 
need evidence that will help us design targeted interventions to influence the quality of care delivered and thereby patient outcomes.

The '7-day services' initiative was introduced in England without a clear understanding of the causes of the weekend effect. The intervention, while well intentioned, was therefore poorly targeted. Rather than a one-size-fits all initiative to increase consultant intensity, we should consider the much harder question on how to spend the same money to maximum effect. Consultant time is scarce and so should be tailored to the time, place and particular conditions where it is most beneficial over the week as a whole. For some patients though, more rapid access to diagnostic tests or the increased use of skilled nurses during recovery may be much more critical to improving outcomes. Studies of the weekend effect drew attention to potentially dangerous levels of staffing that undoubtedly posed risks to patients. At this point, however, we need more precise studies that directly examine standards of care and the factors that influence the care delivered. We can then define and target interventions effectively and make best use of scarce resources.

Funding The authors have not declared a specific grant for this research from any funding agency in the public, commercial or not-for-profit sectors.

Competing interests None declared.

Patient consent for publication Not required.

Provenance and peer review Commissioned; internally peer reviewed.

\section{ORCID iDs}

Perla J Marang-van de Mheen http://orcid.org/0000-0003-

1439-0989

Charles Vincent http://orcid.org/0000-0003-0270-0222

\section{REFERENCES}

1 Bell CM, Redelmeier DA. Mortality among patients admitted to hospitals on weekends as compared with weekdays. N Engl J Med 2001;345:663-8.

2 Chen Y-F, Armoiry X, Higenbottam C, et al. Magnitude and modifiers of the weekend effect in hospital admissions: a systematic review and meta-analysis. BMJ Open 2019;9:e025764.

3 Freemantle N, Ray D, McNulty D, et al. Increased mortality associated with weekend hospital admission: a case for expanded seven day services? BMJ 2015;351:h4596.

4 Honeyford K, Cecil E, Lo M, et al. The weekend effect: does hospital mortality differ by day of the week? A systematic review and meta-analysis. BMC Health Serv Res 2018;18:870.

5 Rimmer A, Kmietowicz Z. BMJ editor writes to Hunt over misuse of weekend mortality data. BMJ 2015;351:h5624.

6 Willis T. Seven days to save the NHS? BMJ Blogs 2015.

7 Rimmer A. Seven day services lack definition. BMJ Blogs 2015.

8 NHS England. NHS services, seven days a week Forum: summary of initial findings. London, 2013.

9 NHS England. Five year forward view. London, 2014.
10 Aldridge C, Bion J, Boyal A, et al. Weekend specialist intensity and admission mortality in acute Hospital trusts in England: a cross-sectional study. Lancet 2016;388:178-86.

11 Gan H-W, Wong DJN, Dean BJF, et al. Do expanded sevenday NHS services improve clinical outcomes? Analysis of comparative institutional performance from the "NHS Services, Seven Days a Week" project 2013-2016. BMC Health Serv Res 2017; 17:552.

12 Meacock R, Sutton M. Elevated mortality among weekend hospital admissions is not associated with adoption of seven day clinical standards. Emerg Med J 2018;35:108-13.

13 Zhou Y, Li W, Herath C, et al. Off-Hour admission and mortality risk for 28 specific diseases: a systematic review and meta-analysis of 251 cohorts. J Am Heart Assoc 2016;5:e003102.

14 Pauls LA, Johnson-Paben R, McGready J, et al. The weekend effect in hospitalized patients: a meta-analysis. J Hosp Med 2017;12:760-6.

15 Smith SA, Yamamoto JM, Roberts DJ, et al. Weekend surgical care and postoperative mortality: a systematic review and meta-analysis of cohort studies. Med Care 2018;56:121-9.

16 Galloway M, Hegarty A, McGill S, et al. The effect of ICU out-of-hours admission on mortality: a systematic review and meta-analysis. Crit Care Med 2018;46:290-9.

17 Chiu C-Y, Oria D, Yangga P, et al. Quality assessment of weekend discharge: a systematic review and meta-analysis. Int J Qual Health Care 2020;32:347-55.

18 Anselmi L, Meacock R, Kristensen SR, et al. Arrival by ambulance explains variation in mortality by time of admission: retrospective study of admissions to hospital following emergency department attendance in England. BMJ Qual Saf 2017;26:613-21.

19 Sun J, Girling AJ, Aldridge C, et al. Sicker patients account for the weekend mortality effect among adult emergency admissions to a large Hospital trust. BMJ Qual Saf 2019;28:223-30.

20 Meacock R, Anselmi L, Kristensen SR, et al. Higher mortality rates amongst emergency patients admitted to hospital at weekends reflect a lower probability of admission. J Health Serv Res Policy 2017;22:12-19.

21 Aiken LH, Sloane D, Griffiths P, et al. Nursing skill mix in European hospitals: cross-sectional study of the association with mortality, patient ratings, and quality of care. BMJ Qual Saf 2017;26:559-68.

22 Griffiths P, Maruotti A, Recio Saucedo A, et al. Nurse staffing, nursing assistants and hospital mortality: retrospective longitudinal cohort study. BMJ Qual Saf 2019;28:609-17.

23 Needleman J, Liu J, Shang J, et al. Association of registered nurse and nursing support staffing with inpatient hospital mortality. BMJ Qual Saf 2020;29:10-18.

24 Halm EA, Chassin MR. Why do hospital death rates vary? N Engl J Med 2001;345:692-4.

25 Bion J, Aldridge C, Girling AJ. Changes in weekend and weekday care quality of emergency medical admissions to 20 hospitals in England during implementation of the 7-day services National health policy. BMJ Qual Saf 2021;30:536-46.

26 Jayawardana S, Salas-Vega S, Cornehl F, et al. The relationship between off-hours admissions for primary percutaneous coronary intervention, door-to-balloon time and mortality for patients with ST-elevation myocardial infarction in England: a registry-based prospective national cohort study. BMJ Qual Saf 2020;29:541-9. 